\title{
Research Needs In Speech Pathology In South Africa
}

\author{
S. BAUMAN, M.A. \\ Assistant Director, Speech, Voice and Hearing Clinic; and Lecturer in the Department of \\ Logopedics, University of the Witwatersrand \\ M. ARON, M.A. \\ Senior Supervisor, Speech, Voice and Hearing Clinic, University of the Witwatersrand
}

Although the field of Logopedics can be regarded as a comparatively recent development in South Africa, it is nevertheless a field that has twenty-five years behind it. This is a fairly considerable period and yet the research yield has been negligible. The natural curiosity which should have led workers in the field to investigate the incidence and nature of speech pathologies in South Africa has been overshadowed by the immediate and urgent need for active therapists who have been given neither the time nor the facilities for research. Therapy has been administered in the main centres for some years now, but there is an ignorance of the circumstances of the speech defective in this country.

The material which presents itself for research in South Africa is rich. Conditions exist here that give rise to many different social strata, different racial and ethnic groups and the existence of many different languages, many of them remote from each other in construction. These facts must obviously play a major role in determining speech standards, the incidence of particular speech defects, attitudes towards the handicapped, etc. A further major aspect that would be most relevant to communication disorders concerns the rapid assimilation that groups are undergoing from a language, ethnic and social point of view. The emergence of new attitudes and standards would be important to study in order to get a clearer picture of how these are initiated and changed.

On considering the type of person who has studied Logopedics in South Africa and the type of employment that has been offered it is not surprising that little research has been done. It is unfortunate that only women have studied in this field in South Africa. This has caused a clinging to town life and usually an immediate break-away from Logopedic practice after marriage. Employment has been restricted to university and hospital clinics, education departments and special schools or institutions, all of which have emphasised therapeutic and training services rather than experimental investigations. We have therefore an unusual and undesirable situation where the cart has been placed before the horse. The Logopedicians are working with groups about whom they know very little. They take for granted and rely uncritically on the research data from other countries and apply them here. This extends into the field of diagnostics and therapeutics.

Apart from the European population (English and Afrikaans-speaking), the Non-European peoples (Coloured, Indian and many groups of Africans) present tremendous scope and difficulties as regards investigation and treatment. Virtually no establishments exist for speech, voice and hearing handicapped Non-Europeans.

The authors believe that work among the NonEuropeans will probably soon be started and that it would be easy to commit the same errors again. Therefore the plea here is for an initial understanding of the material with which we are to work before that material is manipulated therapeutically. Time and space do not permit of the setting out of a complete scientific analysis of the research needs in South Africa. The aspects which confront us in this field are so vast and complicated that in this article we will present only in a "stream of consciousness" some if the ideas which could be used as suggestions for areas of investigation.

\section{SUGGESTIONS FOR AREAS OF INVESTIGATION}

\section{The Influence of Bilinguolism and Polyglotism}

The data from studies on bilingualism and its relation to the incidence of speech defects are by no means conclusive. In the main the studies done in this direction have dealt with the contributory effects of bilingualism on articulatory errors and stuttering.

In South Africa ideal conditions exist for an investigation into this factor for there are many languages spoken here, two of which are English and Afrikaans, the official languages. The facets to this 
problem must be many. However it is felt by the authors that any negative effects of bilingualism can only be brought to bear after the child has been introduced to the two languages for the purposes of expression. In the case of the European child the second official language is, in most cases, introduced after the age of about eight when the child is at school. This is beyond the age when speech can still be considered an inadequate function. It could be said that the greatest contributory cause of bilingualism on speech defects could be when the child is introduced to two languages from an early age as in the case of inter-marriage or newly arrived immigrants from Europe. Investigation here could provide data on the manner in which non-speech defective children acquire a new set of language symbols (taking into account the phonemic structure of the languages concerned). From objective study these errors then would be termed "normal" errors and the child need not necessarily be considered as having a speech defect. Important also would be the data derived from studying the effects of the child experiencing a mixture of languages in the home and later the introduction of the second language in the school situation.

The Coloureds speak in the main Afrikaans but their language is essentially a dialect which becomes a colourful and expressive admixture of Afrikaans, English and slang. The Indian child speaks his home language in addition to the two official languages that are taught in the schools, i.e. English and Afrikaans. The Bantu are usually able to speak more than one African language. In the elementry school he receives some of his instruction in his home language and in addition he is introduced to English and Afrikaans. In the urban areas, particularly in thcir townships, the African tends to become familiar with a number of Bantu languages and English and Afrikaans. He becomes therefore, a polyglot.

All the above groups provide an abundance of material for studying the polyglot individual in terms of the incidence and nature of speech defects directly or perhaps indirectly related to this factor.

\section{Stuttering}

Apart froml the work of Aron (1) concerning urban African Stuttering children, no other information is available on this problem in any other group. The rural African is completely unexplored in this direction. Of particular interest would be the examination of data collected on the rural African child or adult who has not been introduced to any type of schooling or missionary influence. In the cases where stuttering is reported for such groups, it would be interesting to note the reasons why some adult rural Africans "stopped" or "grew out of" stuttering, a factor very often reported by European adults who stuttered when younger.

Although we may assume, both from observation and from our records while servicing schools, that the incidence of stuttering among the Europeans is the usual incidence reported overseas, it should nevertheless be ascertained objectively from studies. Furthermore it would be interesting to note if there would be any differences in incidence and severity among European groups such as the English, Afrikaans and Jewish. From the work among European schools in Johannesburg it is our impression that there tend to be more Afrikaans stutterers than English, which is the converse of what Weiss (2) found.

An interesting, but also as yet unexplored field concerns the Indians. Therapists from the University Speech Clinic working in Indian schools over a period of ten years have found that the incidence of stuttering tends to be higher than that for other groups (2.5 per cent -3.5 per cent). We have little idea about the conditions of this disorder among the Coloureds.

For all these groups, cultural factors cannot be ignored and the symptom complex of this disorder should be studied in relation to differing cultural patterns. Comparative therapeutic measures among these different groups might be difficult to apply but are necessary and information obtained from the reactions and results of these measures could prove most helpful in our understanding of this "will-othe wisp" problem.

\section{Anotomical and Physiological Disorders Affecting Speech and Language}

\section{A. Cleft Polote}

The incidence of cleft lip and palate among the various groups is unknown. We at the University Speech Clinic have never seen an African child with a cleft lip or palate or at least they have never been brought to us. At the same time we believe that the number of Coloured peoples with this condition appears to be high. If this impression is accurate and substantiated by research it could give rise to many speculations and research would be stimulated among the medical profession, geneticists, nutritionalists, etc.

\section{B. Dysphonio}

Professor P. de V. Pienaar believes that the relationship between dysphonic conditions and proximity to gold-mine dumps should be explored. In 
his experience, the fine yellow sand carried in the wind constitutes an irritant.

Some consideration should also bc given to the fact that we have found a large number of dysphonic European school children, particularly in the poorer socio-economic areas.

The Africans appear to have habits not commonly found among other groups that could be related to voice problems among these people. It is quite usual for them to carry on a conversation over distances by shouting as long as the voice can still be heard. They frequently smoke harsh tobaccos and it is common practice to have smoke fires within their kraals. There are apparently voice quality changes depending on traditional cultural and social mores. When talking to authority figures the Zulu, Tshwana and other groups lower the voice. In the same way a wife must address her husband in a low tone which is considered to be respectful. This is accompanied by a bowing position of the body and a clasping of the hands. In tribal singing the women attempt to sing in as high a register as possible. It would be interesting also to study the singing voices of labourers who sing "work songs" while engaged in heavy labour. It is recognised that Bantu languages have colourful tonal and inflectional patterns. To what degree this is carried over into the European languages that they learn and to what degree it influences their communication might be valuable to know.

We have very little idea of the type of dysphonic conditions that might be prevalent among the Coloured and Indian communities. Surveys should be done in this direction in order to supply some data concerning this problem.

\section{Dysarthria and Dysphasia}

The Non-European government hospitals throughout the country admit large numbers of Africans each year who are treated for injuries sustained in accidents and faction fights. Patients with injuries affecting speech, voice or hearing mechanisms could furnish the profession with much valuable data concerning the adaptive and compensatory mechanisms which are adopted by dysarthrics and dysphasics.

Related to the above there is much scope for exploring the recovery process in traumatic as compared with vascular aphasia. Data concerning the nature of disturbed language function in dysphasics who are polyglot may lead to a clearer understanding of the language processes. Aphasic therapy covers language in its spoken and written forms and therefore the treatment of the old generation of Africans who could not read nor write prior to brain injury presents interesting problems. Further interesting comparisons can be made with this group and with those aphasics who seek, on the basis of previous experience and memory to evoke and relate auditory, visual and kinesthetic imagery. Similarly data concerning the recovery process of dysarthric conditions that are traumatic in origin could be of great importance.

\section{Dysaudia}

There are many problems related to deaf and hardof-hearing persons that lend themselves to investigation. Knowing that the African languages use a great deal of intonation variations related to meaning it would be interesting to study the difficulties confronting the African lip-reader. Different methods of teaching lip-reading may be indicated for the different groups in the country.

Related to this would be the study of the melody, rhythm and accent found in the speech of deaf African children as compared with deaf European children.

South Africa is essentially a mining country and the effects of noise (pneumatic drills, etc.) in the mines on the workers could be ascertained for the

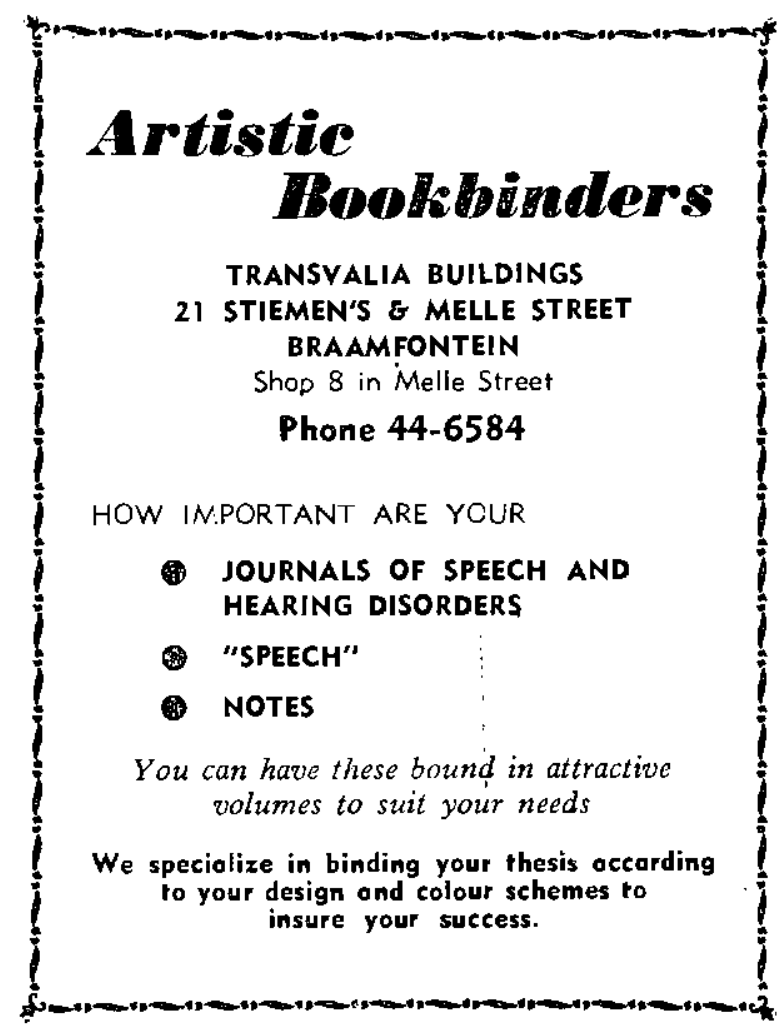


benefit of the many thousands of people employed in this field.

\section{Dyslexio}

Defects of communication in its written forms such as the associated problems of reading and spelling and dyslexia should be investigated among the various groups in South Africa. It should be established what percentage of children suffer from these problems and some attempt should be made to ascertain the factors that are operating causing this problem, whether it be poor teaching methods, poor background of experience, perceptual problems, etc.

Many therapists and other workers have reported that there are many more English children who demonstrate these problems compared to the Afrikaans children and most are in agreement that this is because Afrikaans is a phonetic language while English has many orthographic anomolies. It might be valuable to investigate the possibility of the infiuence in the spelling of a child who is introduced to the second official language in the school situation either in that language or in the previous and presumably home language.

The existence of reading and spelling difficulties that may be present among Bantu school-children in their own languages and in English and Afrikaans is unknown. A study of their approach to these skills may open up new avenues in our understanding of these problems. Biesheuvel (3) who demonstrated differences between the intelligence ratings of Africans and Europeans, found certain perceptual differences, namely manipulating the spatial relations, among African children which he attributed to cultural factors. This significant factor might be operative in their approach to reading.

In relation to the Bantu it would be interesting to see how the adult learns to read and write as distinct from the child and whether the difficulties and errors encountered áre any different from those made by the child.

Each language group in the country requires standardised diagnostic tests, an analysis of the symptomotology and an investigation into vehicles for therapy for children exhibiting reading and spelling difficulties.

\section{Language. Development}

Language development and the form which it takes in each of the different cultural groups could $\mathrm{be}$ studied. It would be important to see whether the forms of speech or language retardation in these groups refiects cultural or other factors.
Rich linguistic experience or poverty of experience might depend not only on cultural influence but also on the socio-economic standard of the group and in this respect rural and urban differences might be noted.

The influence of European standards on African standards might be detected and in the same way the influence of the African nanny on the speech and language development of the young European child might be seen to be significant.

\section{CONCLUSION}

The items discussed above constitute only a very small area in a very vast field. As research projects are undertaken they themselves will bring to the fore more specific problems and indicate the direction of future research.

The research worker in this field faces many problems. Financial assistance has up to the present time not been forthcoming. Perhaps the speech therapists themselves have been at fault here in that they have not impressed upon the authorities the need for this type of work. There are very few models on which this exploratory work could be based in South Africa. Language, social and cultural barriers would hamper the European investigator. At the same time these barriers have been in themselves a deterring factor. Conditions are changing rapidly within the country and the time for research is now.

Approaches should be made to state, university and educational authorities, the Council for Scientific and Industrial Research and other allied organisations so that individual or team projects can go forward to lay the foundations of research. It is incumbent on speech therapists in South Africa to realise this need and to work for the instigation of an active research programme.

\section{References}

1 Aron, M. L. "An Investigation of the Nature and Incidence of Stuttering among a Bantu Group of School-going Children." M.A. dissertation. University of the Witwatersrond. 1958.

2 Weiss, L. "A Study of European Speech Defective School Children in Pretoria." M.A. dissertation. University of the Witwotersrand. 1957.

3. Biesheuvel, S. "African Intelligence". S.A. Institute of Race Relations, Johannesburg. 1943. 